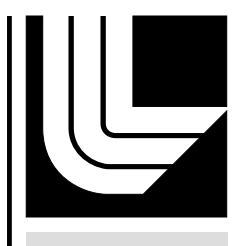

LAW RENCE LIVERMORE N A T IO N A L LABORATORY

\title{
Testing the Physics of Nuclear Isomers
}

A. Hazi

January 27, 2006 
This document was prepared as an account of work sponsored by an agency of the United States Government. Neither the United States Government nor the University of California nor any of their employees, makes any warranty, express or implied, or assumes any legal liability or responsibility for the accuracy, completeness, or usefulness of any information, apparatus, product, or process disclosed, or represents that its use would not infringe privately owned rights. Reference herein to any specific commercial product, process, or service by trade name, trademark, manufacturer, or otherwise, does not necessarily constitute or imply its endorsement, recommendation, or favoring by the United States Government or the University of California. The views and opinions of authors expressed herein do not necessarily state or reflect those of the United States Government or the University of California, and shall not be used for advertising or product endorsement purposes.

This work was performed under the auspices of the U.S. Department of Energy by University of California, Lawrence Livermore National Laboratory under Contract W-7405-Eng-48. 


\section{Testing the Physics of Nuclear Isomers}

OR much of the past century, physicists have searched
for methods to control the release of energy stored
in an atom's nucleus. Nuclear fission reactors have been
one successful approach, but finding other methods to
capitalize on this potential energy source have been elusive.

One possible source being explored is nuclear isomers. An isomer is a long-lived excited state of an atom's nucleus-a state in which decay back to the nuclear ground state is inhibited. The nucleus of an isomer thus holds an enormous amount of energy. If scientists could develop a method to release that energy instantaneously in a gamma-ray burst, rather than slowly over time, they could use it in a nuclear battery.

Research in the late 1990s indicated that scientists were closer to developing such a method-using $\mathrm{x}$ rays to trigger the release of energy from the nuclear isomer hafnium-178m $\left({ }^{178 \mathrm{~m}} \mathrm{Hf}\right)$. To further investigate these claims, the Department of Energy (DOE) funded a collaborative project involving Lawrence Livermore, Los Alamos, and Argonne national laboratories that was designed to reproduce those earlier results.

\section{A Concern for National Defense}

DOE was interested in the hafnium claims because, if verified, they presented new national security issues as well as potential scientific and energy applications. Nuclear isomers with a long lifetime and a high energy release offer the potential to be a standalone energy source. However, if scientists could accelerate an isomer's decay so that gamma rays are emitted in an instantaneous burst, they could also use these isomers to develop propellants and explosives.

"Many applications might be possible if we could duplicate the gamma-ray burst reported in the original research," says Livermore physicist John Becker, who led the tri-laboratory effort. "For example, we might consider developing a gamma-ray laser or a nuclear battery that could power a spacecraft. But we did a textbook nuclear physics experiment, and our results did not match the original claim."

\section{A Nucleus with Energy to Burn?}

A nuclear isomer is an atom whose nucleus is in a higher energy state than its ground state. This excited state is very long- lived compared with the usual lifetimes of excited nuclear states. The long lifetime results because transition to the ground state would require a large change either in the spatial structure of the atom's nucleus (for a shape isomer) or in the angular momentum (a measure of the spin of the nucleus) between the isomer and the nuclear ground state (for a spin isomer). Both types of isomers release energy, usually as electromagnetic radiation, when the nuclei transition from a high energy state to a lower one.

Nuclear isomers have a wide range of lifetimes, radiating away the extra energy anywhere from about a picosecond (one-trillionth of a second) to years. A common nuclear isomer is tantalum$180 \mathrm{~m}\left({ }^{180 \mathrm{~m}} \mathrm{Ta}\right)$, whose half-life is about $10^{15}$ years (a quadrillion years). In its ground state, tantalum-180 $\left({ }^{180} \mathrm{Ta}\right)$ is very unstable and decays to other nuclei in about 8 hours. Tantalum-180 is never found in natural samples, which are billions of years old, but its isomeric state, ${ }^{180 \mathrm{~m} T a}$, is found in natural samples. This metastable excited state has an excitation energy 75 kiloelectronvolts $(\mathrm{keV})$ higher than ${ }^{180} \mathrm{Ta}$, and its decay is inhibited because the angular momentum of the isomer's nucleus is so different from that of the ground state's nucleus.

Hafnium-178m, the isomer studied by Becker's team, has a long half-life of 31 years and a high excitation energy of 2.4 megaelectronvolts $(\mathrm{MeV})$. As a result, 1 kilogram of pure ${ }^{178 \mathrm{~m}} \mathrm{Hf}$ contains approximately 1 million megajoules ( $10^{12}$ joules $)$ of energy. Some estimates suggest that, with accelerated decay, 1 gram of 100 -percent isomeric ${ }^{178 \mathrm{~m}} \mathrm{Hf}$ could release more energy than the detonation of 200 kilograms of TNT.

\section{Reality Check}

To verify the results of the earlier experiments, the tri-laboratory collaboration used Argonne's Advanced Photon Source (APS) as the 
